\title{
The Words "Population" and "Community" Have Outlived their Usefulness in Ecological Publications
}

\author{
William E. Magnusson*
}

Coordenação de Biodiversidade, Instituto Nacional de Pesquisas da Amazônia - INPA, Manaus, AM, Brazil

\begin{abstract}
The concepts of "population" and "community" are so fundamental to the identity of ecological science that their use is almost never questioned, even though many authors have noted that neither has a generally accepted definition. Authors continue to invent new definitions without noting that their definitions will exclude most other ecologists. While there have been many publications questioning the utility of particular lines of ecological enquiry, these have had little effect on ecological practice, and recent ecological papers have few fundamental differences from those published half a century ago, despite the huge advances in analytical techniques. Complaining about others' definitions or suggesting that others should use your definition does not qualify as a method. Here I propose a simple method to increase the utility of ecological publications for conservation that would go far towards solving the problems that have been identified by many authors - stop using the words "population" and "community". The words "population" and "community", as used by ecologists and conservationists, are at best redundant, and almost always retard understanding by scientists and decision makers. The simple expedient of reviewers and editors requesting that authors do not use these words would make authors have to make their methods and assumptions explicit, and the conservation science more useful.
\end{abstract}

Key words: Conservation, Ecology, Community, Population, Communication.

\section{Introduction}

Hodges (2008) argued convincingly that improving definitions does not necessarily improve ecology because "humans are extraordinarily good at understanding meaning from context." I agree with much of what Hodges said, but my interest in the subject started with one of the situations in which she said that precise definitions are necessary - "It is often useful to provide sharply delimited definitions in classes, as we introduce students to concepts." I am not particularly concerned whether ecologists continue to use "population" and "community" in the corridor during coffee breaks. However, as affirmed by Hodges (2008), "In both the numerical and verbal cases, clear operational definitions are critically needed if meaningful ecological understanding is to result".

Participants in publication workshops I coordinated consistently had trouble writing their papers because they did not realize that the apparently dimensionless entities "population" and "community" are scale and observer dependent. Many of these students were established professionals whose papers had been consistently rejected

\footnotetext{
*Send correspondence to: William E. Magnusson

Coordenação de Biodiversidade,

Instituto Nacional de Pesquisas da Amazônia - INPA,

CP 478, CEP 69011-970, Manaus, AM, Brazil

E-mail: bill@inpa.gov.br
}

by reviewers and editors because they had been unable to contextualize their findings. Does the fact that these competent professionals could not get their findings published impede scientific progress? I believe it does, and the simple expedient of reviewers and editors requiring that authors use these terms operationally could increase substantially the number and variety of authors contributing to the ecological literature.

Use of the words "population" and "community" is ubiquitous in the ecological literature. The Google search engine recorded over 16 million hits for "population ecology" and over 45 million hits for "community ecology" in January 2012. Is it possible that these words retard ecological understanding if so many people use them? Here I will try to convince you that this is true, and that ecology and conservation could be advanced by the simple expedient of removing these words from most papers.

\section{Population}

A population is a subset of individuals of a species with some characteristic in common that is of interest to a researcher. In most applied studies of conservation biology, that subset occupies a limited geographic area. Papers published in Wildlife Monographs in 2011 illustrate the sorts of geographic boundaries used by managers. One 
paper studied mule deer in the State of Idaho (Hurley et al. 2011), one studied red-cockaded woodpeckers on military land in the USA (Delaney et al. 2011), and one studied small mammals on 54 experimentally manipulated 1-ha plots (Litt \& Steidl 2011). The "populations" were defined by political boundaries, the research subject, or the sampling units, and this is typical of almost all population ecology.

Much research in genetics has been directed toward the identification of "natural" populations that exist independent of the researcher. However, that line of research has been spectacularly unsuccessful. Waples \& Gaggiotti (2006) p. 1419 stated

We review commonly used population definitions under the ecological paradigm (which emphasizes demographic cohesion) and the evolutionary paradigm (which emphasizes reproductive cohesion) and find that none are truly operational.

The objective is usually to identify groups of individuals that show no genetic spatial structure. However, even though a sample might not be able to detect it statistically, it is extremely unlikely that groups of individuals with no difference in dispersal limitation among themselves exist in nature (Guillot et al. 2009). Rather than absolute categories, it appears that researchers should be looking for subsets of individuals that are relatively homogeneous in relation to a particular question. Stow \& Magnusson (2012) suggested that the software now available to study spatial relationships of individuals makes attempts at defining genetic populations irrelevant and counterproductive. The same is true for demographic studies. If "population" is used to imply some degree of dispersal limitation, why not just describe that limitation and get on with the science?

Given that researchers define populations in relation to their questions, the number of populations contained within a species is proportional to the number of questions that can be asked about that species - i.e, practically infinite. We can conclude that a researcher saying that they studied a population, or group of populations, tells us essentially nothing about their object of study. Worse still, as you probably have preconceptions about what a population is, and your definition of "population" almost certainly does not coincide with that of the author, there will be serious problems of communication. If the researcher had said that they studied the demography of individuals of species X in geographical location Y, you would not have this semantic problem.

\section{Community}

Communities are even harder to define (Wilson 1991; Keddy 1993; Palmer \& White 1994), and this may one of the reasons that Lawton (1999) questioned the relevance of community ecology, though he did not question the equally nebulous concept of "population". Shrader-Frechette \& McCoy (1993) wrote a whole book showing that the concept of community leads nowhere, but gave no alternative except to revert to independent case studies. There has been surprisingly little advance in community ecology in the last 30 years. The summaries of community-ecology studies in Cody \& Diamond (1975) cover most of the concepts being investigated by present-day researchers. Of course there has been discussion as to the relative contributions of chance and deterministic factors (e.g. Strong et al. 1984), but the basic questions remain the same.

No single definition encompasses what most researchers who call themselves "community ecologists" do (Palmer \& White 1994). McGill et al. (2006) stated that "Community ecology is the study of a set of species co-occurring at a given time and place." However, a major line of community ecology studies assembly rules (Diamond 1975). Those assembly rules are usually based on functional traits, but may be indexed through phylogenetic relatedness (Pavoine \& Bonsall 2011), historical contingency (Gould 1989), or just size (Hutchinson 1959). The important thing about assembly rules is that they tell you little about which species can co-occur in space and time, but tell a lot about which species cannot. Therefore, for this line of study, a better definition would be the following: Community ecology is the study of a set of species that cannot co-occur at a given time and place.

Some researchers have even abandoned the requirement of potential co-occurrence. Baker \& King (2010) defined communities based on common responses to environmental gradients. While this potentially defines a subset of species with common requirements, it does not necessarily define what most decision makers would think of as communities. As an extreme example, think of a community defined by requirements for high partial pressure of oxygen. Fish that live in rapids and humming birds that live in forest canopies might have the same breakpoint along an environmental gradient defined by oxygen partial pressure, but few people would consider them to be members of the same community. Of course, you can add other restrictions and only consider species with potential co-occurrence, but the analysis then becomes very complex and you have to define how much potential co-occurrence is sufficient for the organisms to be members of the same community. Defining the "potential" for anything is usually arbitrary.

Use of communities is even more complicated for conservation. Much conservation practice is directed to maintaining species associations that occurred at some point in time (usually the date of European colonization or the advent of intensive agriculture). However, species associations are not stable in time, associations that exist today did not exist in the past, and there is no reason to expect them to occur in the future, independent of environmental degradation (Wiens et al. 2009). This is even more complicated because of the problem of scale. For instance, Litt \& Steidl (2011) studied "communities" of rodents in 1-ha plots, but who considers one ha to be the extent of interspecific associations? 
Defining community boundaries is complex and usually arbitrary. Hubbell's (2001) theory of biodiversity is one of the most cited concepts in the recent ecological literature, and his simulations of meta-communities (a complex of individual communities) produces extremely interesting results. However, each "community" in the initial simulations was composed of only 17 individuals (Hubbell 2001). It is unlikely that many people would consider 17 individuals to compose a community. A model is only simplified reality, but if the modeller is representing something inherently different from that which most people see in the real world, they should use some other word to describe it. Even definitions of communities based on species interactions are extremely scale dependent. Dominant ant species reduce species richness around baits (sampling units covering tens of meters) in studies throughout the world, but they have no detectable effect in sampling units covering hundreds of meters (Baccaro et al. 2012). Most land-use decisions are made at scales much larger than the average coverage of "community" studies, but decision makers are rarely informed about the difficulties of scaling up.

As with populations, communities do not exist independent of researchers' preconceptions, study designs and political requirements. A researcher informing that they studied a "community" tells a decision maker almost nothing useful, and the potential for communication breakdown is as great, or greater, than in the case of the use of the word "population".

The ideas behind the concepts of "population" and "community" are extremely important and have contributed much to the history of ecology. Most people have strong feelings about these words, even though they mean different things to different people, so they have important emotional connotations. Semantically, they are useful to define ecology and separate ecologists from other competing groups in science. Given these attributes, can we afford to abandon them? I believe that we can, and an example of ecologists' use of another word may illustrate the advantages.

\section{Important Words That Impede Communication}

The word "God" represents an extremely important concept for people, and attempts to run societies "scientifically" without the spiritual support of the concept of "God" have not been successful (Armstrong 1993). Arguably, most of society's greatest achievements, and some its worst manifestations, have been obtained through pursuit of the concept of God (Thomson \& Aukofer 2011). We can conclude that the ideas behind the concept of God are extremely important and have contributed much to our history. Most people have strong feelings about this word, even though it means different things to different people, so it has important emotional connotations. Semantically, it is useful to define groups and separate ethnic groups from other competing cultures. That is, it has all the communication characteristics of "population" and "community." However, in contrast to "population" and "community", the word "God" is extremely rare in the ecological literature. I believe that this is because most editors and reviewers, without challenging the importance of the concept, believe that use of the word would not facilitate communication among scientists, or between scientists and decision makers. In fact, because of the lack of definition, and the emotional ties, use of the word is likely to impede communication, as does the use of the words "population" and "community".

I have frequently used "population" and "community" in publications, so I am not just criticizing others. However, in every case, readers would have been better informed if I had defined the object of my study (e.g. the individuals/ species potentially occupying this space in this time) rather than used "population" or "community". If the results represent something more general, it would have been better to explicitly state to what spatial and temporal scales they could be extrapolated, rather than implying that they would apply to any other "population" or "community" of the same taxa. I have no doubt that those papers would have been improved if editors and reviewers had denied me the option of using ecological buzz words.

\section{But Aren't there Other Words with the Same Problems of Definition?}

Of course there are other words used by ecologists that create confusion. Examples include "scale" (Allen \& Starr 1982), "habitat" (Morris 2003), "niche” (Schoener 1989; Godsoe 2010), and "biodiversity" (Magurran 2004). However, if we remove the basic problem, the others become less important. Without "community" and "population", we are forced to be explicit about the spatial and temporal scales to which our results apply. We do not have to appeal to the concept of "habitat", which is just a fuzzy concept of community mixed with the abiotic environment that humans think that organisms use to categorize the world. UNESCOs guide (http://www.unesco.org/csi/pub/source/rs11.htm) states that "what is understood by 'habitat mapping' may vary from person to person". An organism's "niche" is just an undefined extension of its "habitat". These are concepts of external factors to which different organisms are assumed to respond synchronously (community controls). However, they are just patterns caused by species associations that are recognized by humans, which may or may not be of relevance to individual species. There will be as many definitions of a species' "habitat" or "niche" as there are researchers who study it. This is encapsulated in the title of Godsoe's (2010) paper "I can't define the niche but I know it when I see it." Most researchers could substitute "population" or "community" for "niche" in this sentence.

Biodiversity must be one of the most nebulous concepts in ecology, and it is obvious why this should be so. It is a characteristic of an ecological community. If the community does not exist, neither does its biodiversity. Ecologists 
have tried to get around this by defining diversity without defining the community, and this has lead to some strange relationships that are not understood by people in the street. For instance, one of the most widely used indices of biological diversity is Shannon's H. Shannon developed the index to evaluate how much information was in a single letter (he was a code breaker). Although it tells you how much information is in the average letter (good to know if you are breaking codes), it does not tell you how much information is in the message. The way it is used in ecology, it tells you how much information is given by the capture of a single individual, but very little about how much information is in the "community". This leads to some counterintuitive results. Shannon's index of diversity should generally decrease as phylogenetic, morphological, physiological and trophic diversity increases because of the strong relationships between density of individuals and these factors (Magnusson 2002). Although this apparently does not present problems for theoretical ecologists, other segments of society may have trouble understanding its relevance.

Almost all diversity indices can be derived from the table used to generate a species-accumulation curve (Pélissier et al. 2003), also known as a collector's curve, and this pinpoints the problem. They reflect how we sample. We no longer have to deal with arbitrary limits to our "community" (or "population" if we are dealing with intraspecific genetic diversity), but we are faced with arbitrary decisions about how to sample. The values of the indices therefore reflect the behaviour of the researcher rather than the characteristics of the "community". Fisher's alpha is less sensitive to samplingunit size (but not distribution) than other diversity measures (Condit et al. 1996), but requires that species abundances in all "communities" follow a particular distribution that is derived from sampling theory. If sampling was not done according to theory (random sampling, with the chance of being included in the sample the same for all individuals), conclusions based on sampling theory will not apply.

Ecologists recognize that the number of species (or any other measure of "diversity") does not increase linearly with sampling area, and this has lead to the concepts of alpha, beta and gamma diversity. Alpha diversity is arbitrary, because it just reflects the decision of the researcher as to what size of sampling unit to use. Gamma diversity would be fixed if we could define the limits of the "community", but of course we can't, so we use some arbitrary limit. Beta diversity can be calculated in various ways from alpha and gamma diversity, but, as these are arbitrary, beta diversity is also arbitrary. Tuomisto $(2010 \mathrm{a}, \mathrm{b})$ tried to find workable definitions of beta and gamma diversity, but in the end accepted that they must be calculated from the data provided by the researcher. That is, they are likely to be useful to describe researcher behaviour, but not much else.

Any basic statistics book explains that a sample is only useful if it is representative of the whole object that is being described. That is, where possible, we should take a random sample across the whole area of inference. If we cannot define the area of inference (the "population" or "community"), we cannot sample it randomly, so none of the indices that we use to describe it will be valid. Even if we could define the limits to our study concepts, we cannot sample them without error. That is, we have to take into account false absences (Williams et al. 2002). However, to date, corrections for false absences in community studies have been limited to the least interesting index, the average number of species occurring in a sampling unit (species richness).

Typically, researchers make observations on individuals and want to scale up, so they start to study a "population" (demography), but soon learn that sampling problems make this a difficult task, especially if the "population" covers something larger than the sampling unit. Therefore, they take the "easy" option of studying all species in the "community" simultaneously. Once into the more nebulous community area, sampling theory seems less important, even though any viable sampling strategy will have different biases for different species (i.e the probability of being included in the sample differs between individuals of different species). This is especially problematic for indices that take into account relative densities. There is little evidence that the proportions of individuals sampled for any taxonomic group have anything to do with the proportions of the species in the field (i.e. in the "community"). Moving from "population" to "community" has in fact compounded all our sampling problems, but has the advantage that the data are now so complex that we, and others, have difficulty recognizing the problems. We have moved from an emphasis on what occurs in the field to an emphasis on the artefacts of researcher behaviour.

\section{Where to Go From Here?}

Hodges (2008), suggested that terms with many modifiers are probably good signals for concepts that do not have satisfactory classification schemes. However, terms that generally do not carry modifiers, such as "population" and "community" are not necessarily mature. It is more a sign that researchers have given up trying to get operational definitions (that require modifiers) and are content to imply that the term represents anything from individuals in a sampling unit to an assemblage of species interacting across a continent. This convenience carries a heavy price when it comes to convincing reviewers and editors that the results deserve to be published.

If this is not to be just another empty criticism, I must suggest alternatives. Rather than study populations (undefined objects), we can study demography (processes) of groups of individuals that we define in each study in relation to our questions. Rather than do community ecology, (which implies an object with geographical limits) we can do species-association or species-interaction studies (studies of processes), each within an ecological space defined by taxa, physical space and time. A study of process will require 
definition of space in the methods. A study of an object comes with an implied space that the object occupies that usually is not defined in the methods. I realize that these suggestions will elicit strong emotional reactions, especially from those interested in maintaining our ecological traditions. However, before discarding the idea, I urge you (especially reviewers and editors) to try eliminating "population" and "community" from texts wherever possible and see if it does not improve communication between writers and readers, especially between scientists and decision makers. It may be the most effective method to increase the utility of the results of conservation studies.

\section{Acknowledgements}

The ideas behind the genetic aspects referred to in this paper were developed during collaboration with Adam Stow, and the extent to which "population" and "community" reduce communication became apparent in publication workshops promoted by the National Institute for Science, Technology and Innovation for Amazonian Biodiversity (INCT-CENBAM), the Brazilian Program for Biodiversity Research (PPBio), and the CNPq PELD program of the Ministry of Science, Technology and Innovation (MCT), and PROCAD collaborations financed by the Coordenação de Aperfeiçoamento de Pessoal de Nível Superior (CAPES) of the Ministry of Education (MEC). Although he does not agree with my conclusions, a review by Leandro Duarte substantially improved the manuscript.

\section{References}

Allen TFH \& Starr TB, 1982. Hierarchy: perspectives for ecological diversity. Chicago: University of Chicago Press.

Armstrong K, 1993. A history of God. New York: Ballantine Books.

Baccaro FB et al., 2012. Limited effects of dominant ants on assemblage species richness in three Amazon forests. Ecological Entomology, 37:1-12. http://dx.doi. org/10.1111/j.1365-2311.2011.01326.x

Baker ME \& King RS, 2010. A new method for detecting and interpreting biodiversity and ecological community thresholds. Methods in Ecology and Evolution, 1:25-37. http://dx.doi.org/10.1111/j.2041-210X.2009.00007.x

Cody, ML \& Diamond JM, 1975. Ecology and evolution of communities. Cambridge: Belknap Press.

Condit R et al., 1996. Species-area and species-individual relationships for tropical trees: a comparison of three 50-ha plots. Journal of Ecology, 84:549-562. http://dx.doi. org/10.2307/2261477

Delaney DK et al., 2011. Response of red-cockaded woodpeckers to military training operations. Wildlife Monographs, 177:1-38. http://dx.doi.org/10.1002/wmon.3

Diamond JM, 1975. Assembly of species communities. In: Cody ML \& Diamond JM, editors. Ecology and evolution of communities. Cambridge: Belknap Press. p342-444.
Godsoe W, 2010. I can't define the niche but I know it when I see it: a formal link between statistical theory and the ecological niche. Oikos 119:53-60. http://dx.doi. org/10.1111/j.1600-0706.2009.17630.x

Gould SJ, 1989. Wonderful life: the Burgess shale and the nature of history. New York: W. W. Norton.

Guillot $\mathrm{G}$ et al., 2009. Statistical methods in spatial genetics. Molecular Ecology, 18:4734-4756. PMid:19878454. http:// dx.doi.org/10.1111/j.1365-294X.2009.04410.x

Hodges KE, 2008. Defining the problem: terminology and progress in ecology. Frontiers in Ecology and Environment, 6:35-42. http://dx.doi.org/10.1890/060108

Hubbell SP, 2001. The unified neutral theory of biodiversity and biogeography. Princeton: Princeton University Press.

Hutchinson GE, 1959. Homage to Santa Rosalia, or why are there so many kinds of animals? American Naturalist, 93:145-159. http://dx.doi.org/10.1086/282070

Hurley MA et al., 2011. Demographic response of mule deer to experimental reduction of coyotes and mountain lions in southeastern Idaho. Wildlife Monographs, 178:1-33. http:// dx.doi.org/10.1002/wmon.4

Keddy P, 1993. Do ecological communities exist? A reply to Bastow Wilson. Journal Vegetation Science, 4:135-136. http://dx.doi.org/10.2307/3235741

Lawton JH, 1999. Are there general laws in ecology? Oikos, 84:177-192. http://dx.doi.org/10.2307/3546712

Litt AR \& Steidl RJ, 2011. Interactive effects of fire and nonnative plants on small mammals in grasslands. Wildlife Monographs, 176:1-31. http://dx.doi.org/10.1002/wmon.2

Magnusson WE, 2002. Diversity indices: multivariate candies from Pandora's box. Bulletin Ecological Society of America, 83:86-87

Magurran AE, 2004. Measuring Biological Diversity. Oxford: Blackwell Publishing.

McGill BJ et al., 2006. Rebuilding community ecology from functional traits. Trends Ecology Evolution, 21:178-185. PMid:16701083. http://dx.doi.org/10.1016/j.tree.2006.02.002

Morris DW, 2003. Toward an ecological synthesis: a case for habitat selection. Oecologia 136:1-13. PMid:12690550. http://dx.doi.org/10.1007/s00442-003-1241-4

Palmer MW \& White PS, 1994. On the existence of ecological communities. Journal Vegetation Science, 5:279-282. http:// dx.doi.org/10.2307/3236162

Pavoine SM \& Bonsall B, 2011. Measuring biodiversity to explain community assembly: a unified approach. Biological Reviews, 86:792-812. PMid:21155964. http:// dx.doi.org/10.1111/j.1469-185X.2010.00171.x

Pélissier R et al., 2003. Consistency between ordination techniques and diversity measurements: two strategies for species occurrence data. Ecology 84:242-251. http://dx.doi. org/10.1890/0012-9658(2003)084[0242:CBOTAD]2.0.CO;2

Schoener TW, 1989. The ecological niche. In: Cherret JM, editor. Ecological concepts. Oxford: Blackwell Scientific Publications. p. 79-113. 
Shrader-Frechette KS \& McCoy ED, 1993. Method in ecology: strategies for conservation. Cambridge: Cambridge University Press. http://dx.doi.org/10.1017/CBO9780511623394

Stow, A \& Magnusson WE, 2012. Genetically defining populations is of limited use for evaluating and managing human impacts on gene flow. Wildlife Research, 39:290-294.

Strong DR et al., editors, 1984. Ecological Communities. Princeton: Princeton University Press.

Tuomisto H, 2010a. A diversity of beta diversities: straightening up a concept gone awry. Part 1 . Defining beta diversity as a function of alpha and gamma diversity. Ecography, 33:2-22. http://dx.doi.org/10.1111/j.1600-0587.2009.05880.x

Tuomisto H, 2010b. A diversity of beta diversities: straightening up a concept gone awry. Part 2. Quantifying beta diversity and related phenomena. Ecography, 33:23-45. http://dx.doi. org/10.1111/j.1600-0587.2009.06148.x
Thomson TJ \& Aukofer C, 2011. Why we believe in God(s). Charlottesville: Pitchstone Publishing.

Waples RS \& Gaggiotti O, 2006. What is a population? An empirical evaluation of some genetic methods for identifying the number of gene pools and their degree of connectivity. Molecular Ecology, 15:1419-1439. PMid:16629801. http:// dx.doi.org/10.1111/j.1365-294X.2006.02890.x

Wiens JA et al., 2009. Niches, models, and climate change: assessing the assumptions and uncertainties. PNAS, 106(suppl. 2):19631-19638. PMid:19822750 PMCid:2780938. http://dx.doi.org/10.1073/pnas.0901639106

Williams BK, Nichols JD \& Conroy MJ, 2002. Analysis and Management of Animal Populations. San Diego: Academic Press.

Wilson JB, 1991. Does Vegetation Science exist? Journal Vegetation Science, 2:289-290. http://dx.doi. org/10.1111/j.1654-1103.1991.tb01131.x

Received: June 2012

First Decision: September 2012

Accepted: December 2012 